\title{
Research on the relationship between human behaviour and climatic characteristics in a public open space. Survey and analysis in Saitama New Urban Centre area
}

\author{
Kaoru Matsuo \\ Osaka Prefecture University, Japan \\ kmatsuo@envi.osakafu-u.ac.jp
}

Rui Izumiyama

Nihon University, Japan

izumiyama.rui@nihon-u.ac.jp

\author{
Shihona Arai \\ Capital Region Comprehensive Planning Institute Co. Ltd., Japan \\ shnaug-II@hotmail.co.jp
}

Akiko Tanimura
Planning Plus Co. Ltd.
a.tanimura@planning-p.com

\author{
Yusuke Horie, Riki Nomoto \\ Showa Co.,Ltd. \\ yusuke_horie@sho-wa.co.jp | riki_I80II@sho-wa.co.jp
}

\begin{abstract}
In urban area, making the attractive public spaces is effective one way of creating a public life or increasing the value of area. In Japan, there have been many public spaces which are not well used because the flexible utilization of public spaces including road, park and river has been limited due to some regulations. However, in accordance with the revision of "Act on Special Measures concerning Urban Reconstruction" and so on, stakeholders have been able to review the making public spaces which are stimulated flexibility use because the utilization of public spaces have been permitted by private business operators or locally area management association. In case of practical and tactical public space making, it is necessary to gain a public consensus through stakeholders discuss what kind of good effect will be made by the alteration of public spaces by communication. Therefore, it is effective to visualize based on the data verification and accumulate the results for short-term and temporary alteration of public spaces such as social experiment. At the same time, integrating the consideration of thermal environment and wind condition will contribute to make more attractive public spaces. Therefore, this study aims obtaining the basic data necessary for making the attractive public spaces considering thermal environment and wind condition in Saitama New Urban Center Area which is central business zones. Specifically, this study progressed via the following steps: I) activity investigation; 2) thermal environmental and wind condition survey and numerical simulation results; 3 ) analysing the relationship between I) and 2). In addition, it attempts to make analysis focusing strong wind for high-rise building because the high-rise buildings are lined in many parts of Saitama New Urban Centre Area. Also, these results are intended to make use of designing attractive public spaces in Saitama New Urban Center Area.
\end{abstract}

Keywords: wind, solar radiation, pilot project, public open space, CFD, actual behaviour of users

To cite this article:

Matsuo, K., Izumiyama, R., Arai, S., Tanimura, A., Horie, Y., Nomoto, R. (2020). Research on the relationship between human behaviour and climatic characteristics in a public open space: Survey and analysis in Saitama New Urban Center area, The Journal of Public Space, 5(2), I I I-I28, DOI 10.32891/jps.v5i2.1 I55

This article has been double blind peer reviewed and accepted for publication in The Journal of Public Space.

(c) (-) $\$$ This work is licensed under a Creative Commons Attribution - Non Commercial 4.0

International License https://creativecommons.org/licenses/by-nc/4.0/ 


\section{Background and objective}

In Japanese cities, many public open spaces have been recently developed to ensure a comfortable urban environment under the 'Urban Development Systems' which are district plans that stipulate redevelopment promotion areas, specified blocks, high-level use districts, and planned development design system. In the metropolitan centre, attractive public open spaces have been purposeful developed to create a vibrant atmosphere that people find appealing. Until now there have been many public open spaces in Japan that have not been utilized to their full potential due to heavy regulation. The following types of public spaces are affected: roads, parks and river fronts. However, following the latest revision of the 'Act on Special Measures concerning Urban Reconstruction' (Tokyo Metropolitan Government, n.d.) and other related regulations, stakeholders can now review the development of public spaces. These spaces have been imbued with life due to permissibility of flexibility as they are privately operated by businesses or local area management associations. For example, the "Tokyo Municipal Ordinance on promoting the creation SHARETA-MACHINAMI of Tokyo (Izumiyama et al., 2015)" has been introduced for improving the image of Tokyo. Prior to the introduction of the new system, only public benefit events were permitted; however, now it is possible to open cafes, sell goods, and organize events that require a participation fee (Izumiyama et al., 20 I5; Izumiyama et al., 20 I6; Izumiyama et al., 20 I8). In case of tactical public open space, it is necessary to gain a public consensus through stakeholders and discuss the kinds of positive effects the alteration of public open spaces will have via communication or active engagement (Wai et al., 20I8). Therefore, it is effective for stakeholders to visualize and accumulate the results for short-term and temporary alteration of public spaces such as the pilot project titled "Tactical Urbanism" (Lydon \& Garcia, 20I5). Many studies have analysed the relationship between temporary objects through small scale pilot intervention and consequently the change in human activity. For instance, the relationships between temporary objects related to parasol gallery and communicative or stationary behaviours of people were analysed at the underground pedestrian road opposite Chiba station ( $\mathrm{Li}$ et al., 20I2). The study finds that elucidated that setting of temporary objects and the making temporary spaces could change the underground pedestrian road, which is used just for the purpose of crossing into a lively space. Moreover, a study conducted at a mall in Ichiki-Kushikino city, Kagoshima, examined the effects of chair utilization rate and space uses by setting temporary parasol or chairs in a public open space (Okamatsu \& Mouri, 20I5); the findings revealed a relationship between types of events and chair utilization rate and uses. These studies have elucidated that the number of pedestrians or stationary people and their behaviours are related to the objects in public open spaces.

Furthermore, the factor of the number of pedestrians or stays around people and their behaviour is not limited to only chairs, tables, etc.; rather, it encompasses entirety of the micro-climate in public open spaces. Gehl and Gehl Architects (2009) regarded microclimates as an evaluation tool for public open spaces. Morita et al. (20I5) showed that when a pilot project is conducted at a wooden terrace (public open space), outside temperature and weather can strongly affect pedestrian route choices. In addition, Akagawa et al. (2007) analysed the relationship between the observed climate data (temperature, wind, and solar radiation) and the number of stationary people or visitors

\footnotetext{
' See http://www.toshiseibi.metro.tokyo.jp/cpproject/intro/description_I.html
} 
at a large rooftop garden; this study revealed that the correlation coefficient between the observation results and the number of stationary people is high but negative, in public open spaces without a green shady area on a sunny day. Nakase and Kiyota (1988) recognized the relationship between thermal factors and stationary people in parks and surroundings in Osaka. They highlighted that the relationship between the stationary behaviours and the thermal factors (temperature, surface temperature, and shade) is relatively high during spring season.

Consequently, integrating the consideration of thermal environment (temperature, surface temperature, and shade) and wind condition is considered effective when comfortable public open spaces are designed based on pilot project learnings. However, in order to carry out such design and plans, it is necessary to better understand the climatic characteristics such as thermal environment and wind condition as not points but spatial distribution. This study aims to better understand the relationship between numerical simulation of spatial distribution results and investigation results of the actual user behaviour. Moreover, it also examines the creation of a street environmental climate map for human activity for planning comfortable public spaces considering climatic characteristics in Saitama New Urban Center (SNUC) area, which is a central business zone. For the purpose of this study, the human activity investigation data was obtained through the pilot project titled, "Public Life Fes Saitama Shintoshin 2018” in SNUC.

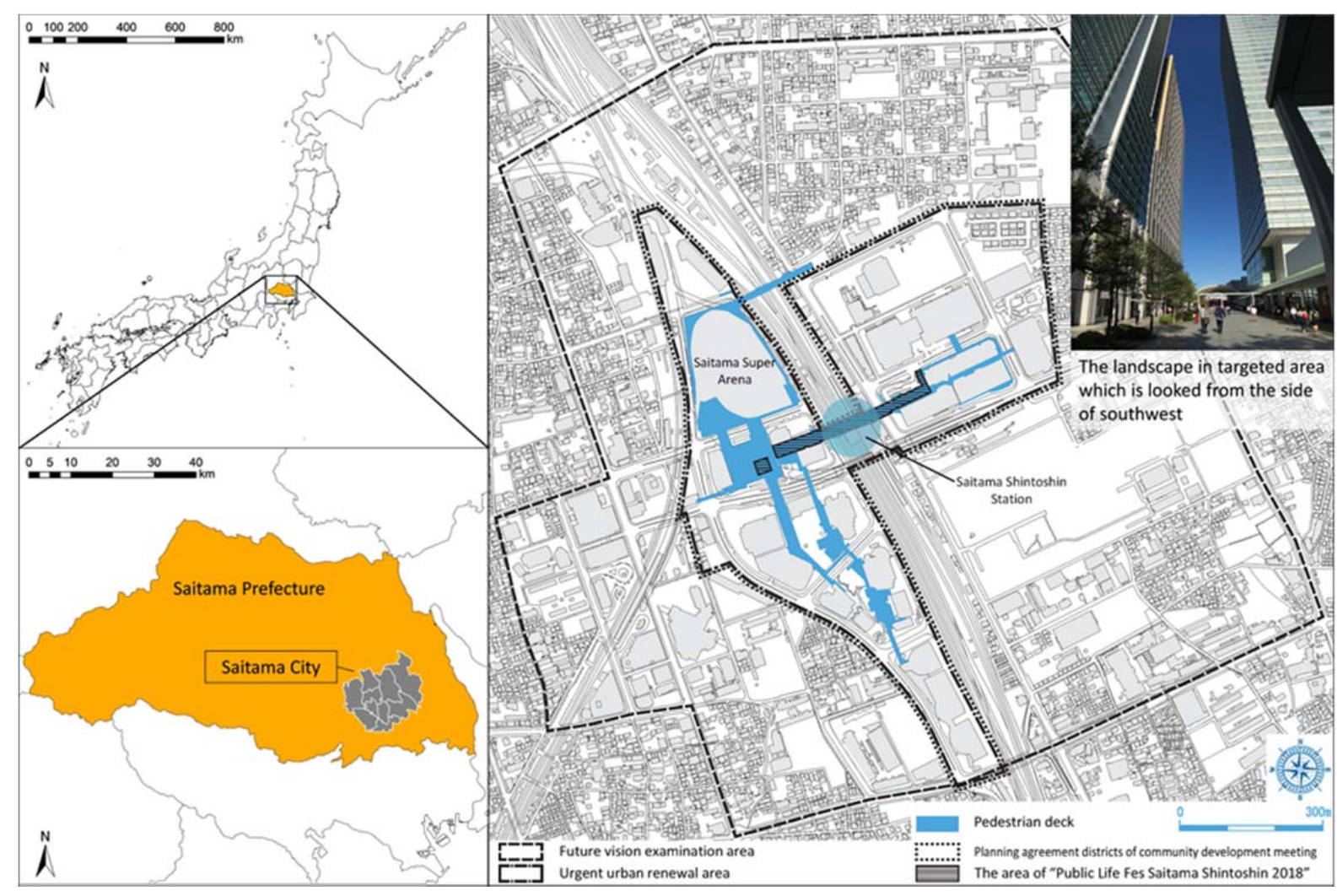

Figure I. Outline of targeted area (Source:Authors). 


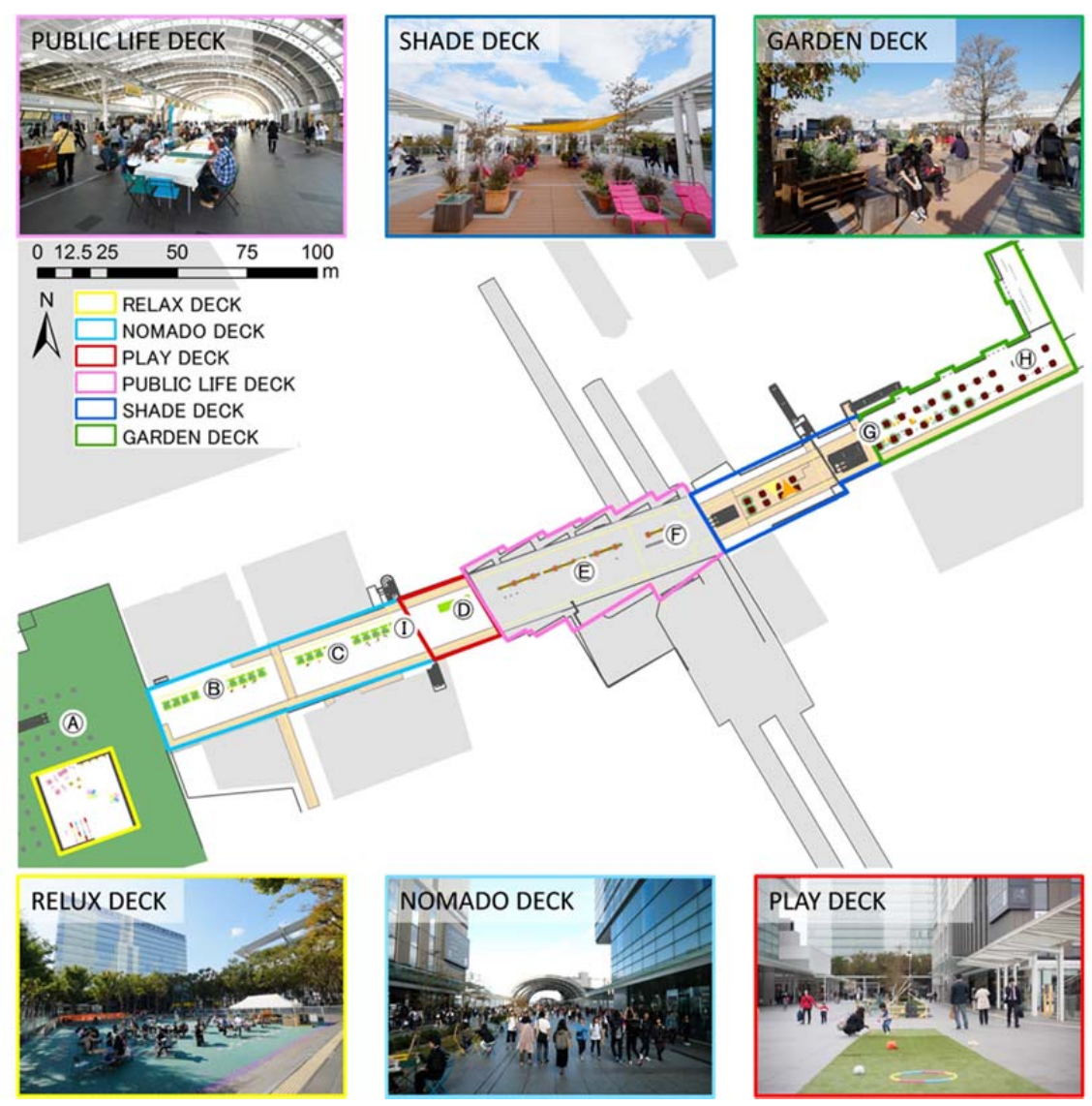

Figure 2. Outline of pilot project area and location of wind fixed points observation (Source:Authors).

\section{Research outline}

\section{I. Study area}

'Saitama New Urban Center (SNUC)' was selected as the target area (Figure I). SNUC was a district that was redeveloped as 'Land Readjustment Projects in Saitama New Urban Center' in 1986 (Urban Renaissance Agency, n.d.). In this project, public facilities were improved as part of the upgrade of the city function in which the former Japanese National Railways Omiya Yard forms the business core are of the city positioned within in the metropolitan area as an attractive new city centre that integrates the city functions, leading industries and the cultural hub of the central city area of Saitama. Currently, SNUC Station, high-rise commercial buildings or offices buildings, Saitama Super Arena, etc. were also planned and built. In addition, pedestrian decks connect these buildings. They were constructed on the second-floor level above ground. Currently, the 'SNUC Town Development Promotion Council' (Saitama city, 20 I4), which comprises members centred on landowners, has been founded in order to promote town development activities such as landscape maintenance and barrier-free planning and design principles. Nineteen years have passed since the city opened and there is a growing need for initiatives to improve the value of the area, such as aging of the city's infrastructure and renewal of signs, information dissemination of the area, and further public space utilization. As for the wind condition in this area, there are strong winds on 
the pedestrian decks caused by the positioning of the surrounding skyscrapers. A preparatory interview survey revealed that many people consider the strong winds a serious problem in this area. The basic information related to SNUC is as follows:

- Developing area: $47.4 \mathrm{ha}$

- Total floor area: $1,800,000 \mathrm{~m}^{2}$

- Total number of employed people: 57,000

\subsection{Outline of SNUC pilot project}

The pilot project, “Public Life Fes Saitama Shintoshin 2018” was conducted from October 15 to 24,2018 . The project objective was to promote daily utilization of the public open spaces for office workers, residents and visitors. For the duration of the pilot project, temporary objects were implemented in six target areas (Figure 2): “GARDEN DECK”, “SHADE DECK”,"PUBLIC LIFE DECK”,“PLAY DECK”, “NOMADO DECK" and "RELAX DECK." The six areas were set up based on the pre-survey results obtained in June which revealed issues in each deck that discouraged stationary behaviour. Each of the areas was designed and modified in such a way as to encourage people to stay and engage in stationary behaviours. Furthermore, the pilot project was hosted by landowners, surrounding companies, and the government. The content of the pilot project based on the pre-survey results of each area is described below.

GARDEN DECK:This area was a space where people passed through and no stationary behaviours occurred. Thus, the design concept was to create a relaxed environment where mall visitors and students who came and went could be soothed by the greenery. In order to make such a space, vegetation was arranged on the deck and lighting production was switched on at night.

SHADE DECK: In this space, stationary behaviours occurred in the evening as well as during the day when there was shade. The design concept was the creating of a relaxed environment where people would feel comfortable in the shade or enjoy the breeze. In order to make such a space, objects placed included tarp, chairs, and an existing bench. PUBLIC LIFE DECK: In this area, a range of stationary behaviours occurred - except human conversation - as the area is near ticket gate and benches were installed that are wider that people not necessarily sit and face towards each other. The design concept was to create a main area that represents the essence of Saitama Shintoshin in which different industry groups can interact. In order to design such a space, long tables, chairs and a welcome board were installed.

PLAY DECK: No stationary behaviour such as taking short break occurred, but a device using the characteristics of the place was installed. The design concept was to create a relaxing environment where children could play safely. In order to set up the area, artificial grass was installed. Thus, stationary activity in this area constituted of child play on artificial grass and their parents talking or interacting nearby.

NOMADO DECK:The design concept was to create a relaxing environment where people can feel comfortable even alone. The setup included tables, chairs and a food stall. In this case, stationary behaviour included workers of nearby companies taking a break or having a professional meeting with food and drinks.

RELAX DECK:This design concept was also to create a relaxing environment where everyone including workers or visitors could relax. The setup consisted of a small outside office and a recreation space. Here, the stationary activity of people included workers from nearby companies having job meetings or even practicing yoga. 


\subsection{Method}

This study was undertaken according to the following steps.

I. Investigation of the actual behaviour of users

2. Meteorological observation

3. Simulating of wind distribution and the amount of solar radiation distribution based on computational fluid dynamics (CFD) uses numerical methods and algorithms to analyse and solve problems involving fluid flow

4. Relation analysis of results of I) and 3)

5. Climate zoning for development of street environmental climate map

\section{Investigation of the actual behaviour of users}

\section{I. Number of pedestrians}

The average number of pedestrians and their walking direction were investigated at 10 points in the pilot project area on October 19 (weekday) and 20 (holiday) (Figure 3).

The weekday data revealed that the number of pedestrians was highest at point 4 and 5 while point 3 and 6 had the second highest numbers; the number of pedestrians decreased as the distance from station increased. Moreover, in the western area, the number of pedestrians was the highest at point 7 , which is connected to the administration area, while it was the lowest at point 8 , which is connected to the Saitama Super Arena. The weekday data revealed that the number of pedestrians was at its highest at point 5 , and second highest at point 8 . Relatively few people were walking to the south side of the pedestrian deck. And at point 2 , the number of pedestrians increased more than weekday. Generally, the number of pedestrians was higher on a holiday than on the weekdays.
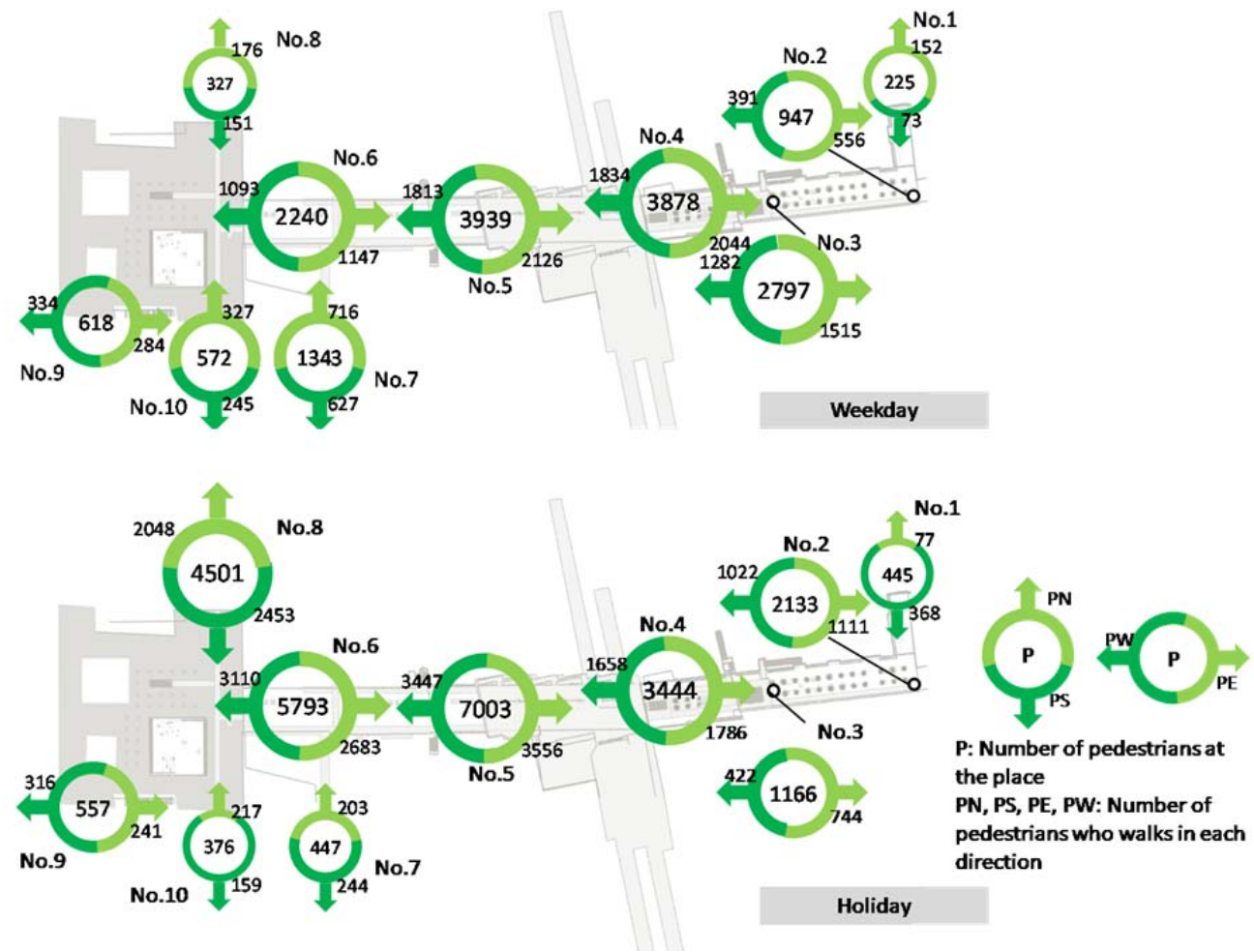

Figure 3. Number of pedestrians (Source: Authors) 


\subsection{Activity surveys}

Human activities were investigated in the area on October 19 and 20. Figure 4 shows the spatial distribution of stationary people on a weekday and a holiday. The results indicated that most of the stationary people were located near the station and with relatively few people on the "NOMADO DECK". Furthermore, the number of stationary people during the holiday on the "SHADE DECK", "GARDEN DECK" and "PLAY DECK" was higher than that on weekdays. Figure 5 depicts the hourly number of stationary people according to some activity groups in the part of the "GARDEN DECK”,"SHADE DECK” and "PUBLIC LIFE DECK”.

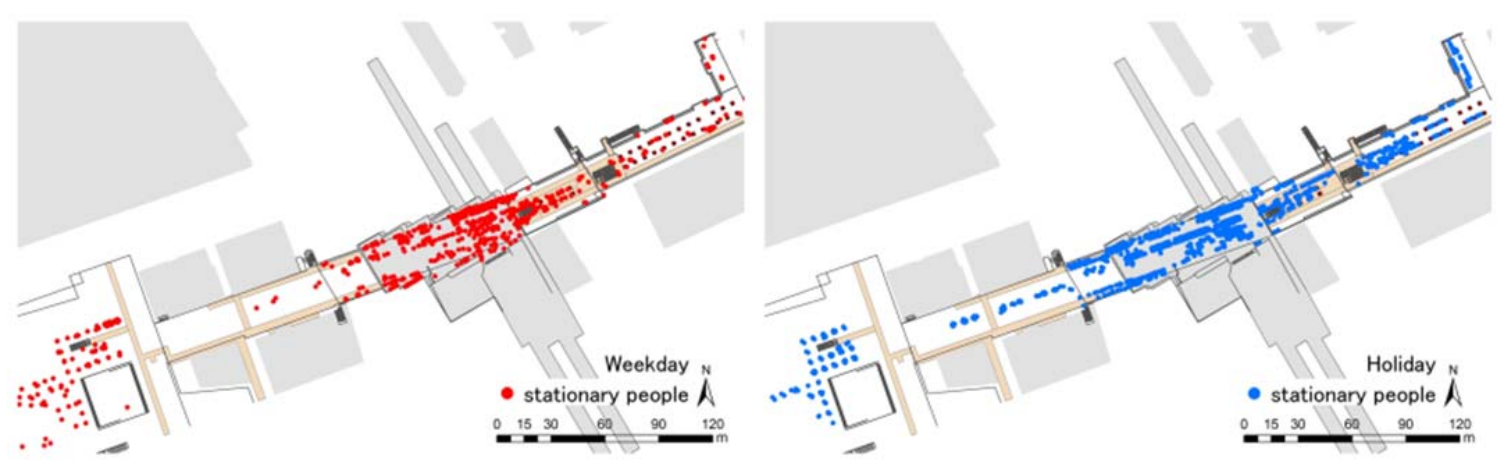

Figure 4. Stationary people distribution (Source: Authors)
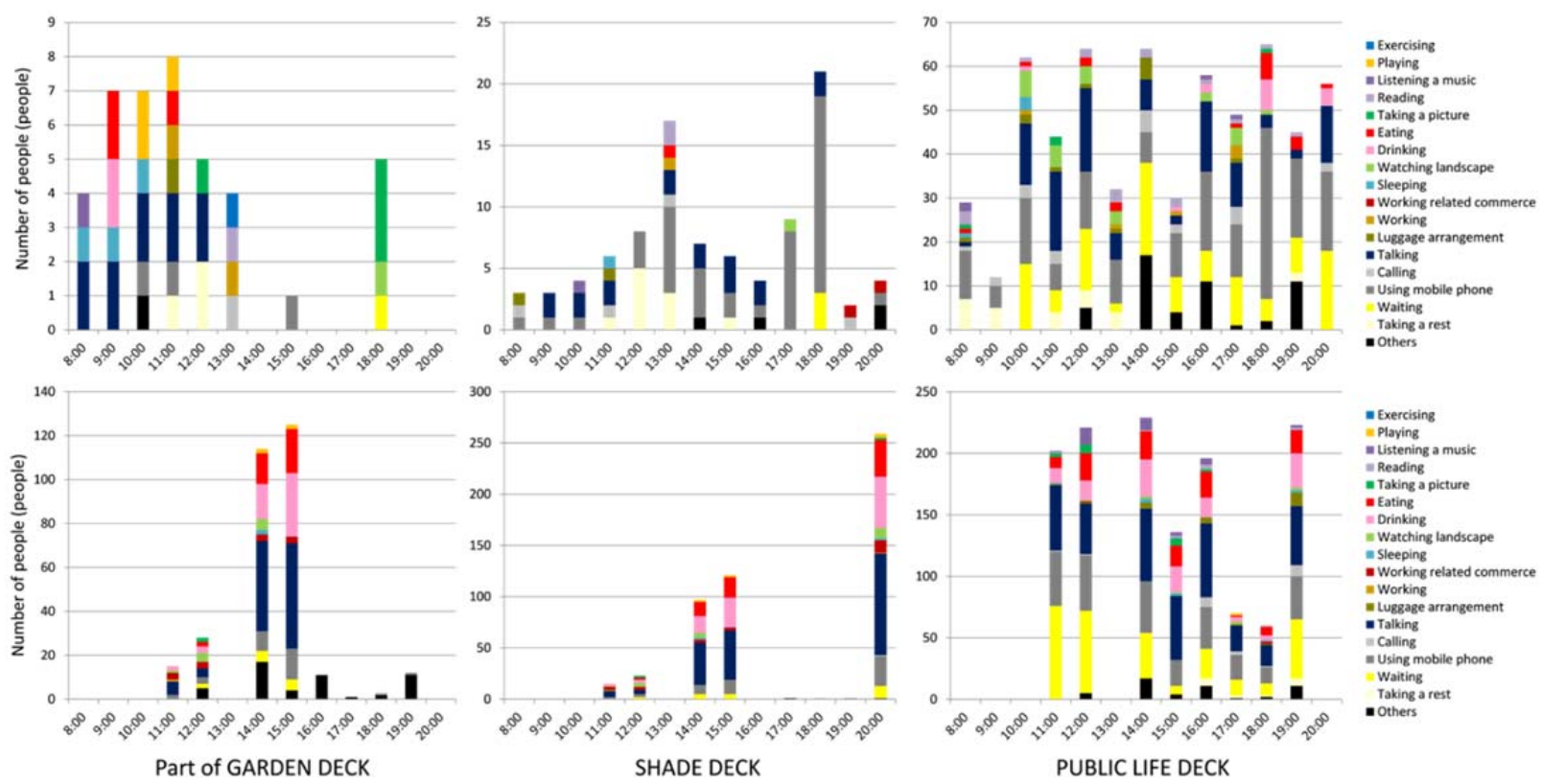

Figure 5 . Hourly number of stationary people according to some activity groups (upper side is on weekday and lower side is on holiday) (Source: Authors)

The part of "GARDEN DECK" is the lower area of L-shaped area of "GARDEN DECK". On the part of the "GARDEN DECK" weekdays, the number of stationary people was relatively large in the morning and many people were communicating at any time. During holidays, the number of stationary people was relatively large at around 14:00 or 15:00. 
On the one hand, on "SHADE DECK" during weekdays, the number of stationary people was relatively large at around 13:00 or 18:00 with many people using mobile phone devices. On the other hand, on holiday, the number of people who were talking, eating or drinking was larger than the number of people using mobile phone devices. On "PUBLIC LIFE DECK" the number of stationary people was the highest among the three zones and many people were observed waiting, although they were not necessarily sighted in other zones. Also, the number of people having conversation was the same as those using mobile phones devices or waiting for someone.

According to the above results, there were many pedestrians and stationary people in front of the station which indicates that the area is slightly different compared to other areas. The number of stationary people in the eastern part of the area was higher than that in western part. Regarding the types of activities, there were a many people having conversation or using their mobile phone devices. If weekday and holiday activities were compared, data shows that in comparison to weekdays, more people were drinking and eating during holidays.

Oct. 19 (Weekday)

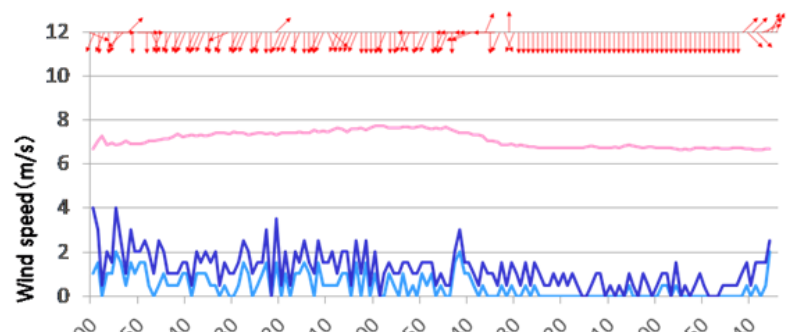

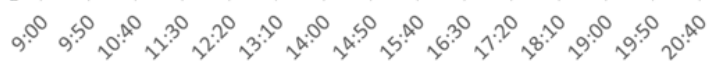

Oct. 20 (Holiday)

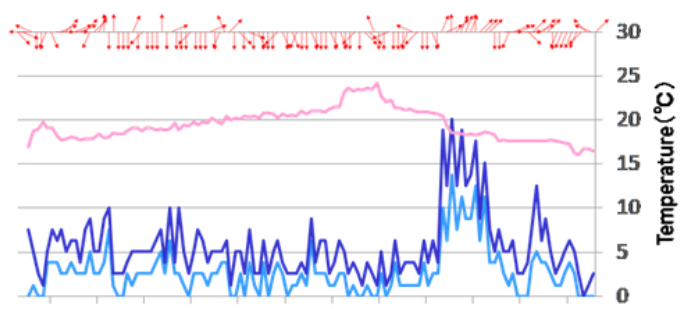

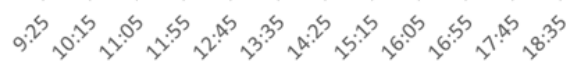

$\begin{array}{llll}\longrightarrow & \text { Temperature } & & \text { Maximum instantaneous wind speed } \\ & \text { Average wind speed } & \longrightarrow & \text { Wind direction }\end{array}$

Figure 6. Maximum instantaneous wind speed, average wind speed, wind direction, and temperature on Oct. 19 and 20 in point I (Source: Authors; graphs generated based on open data)

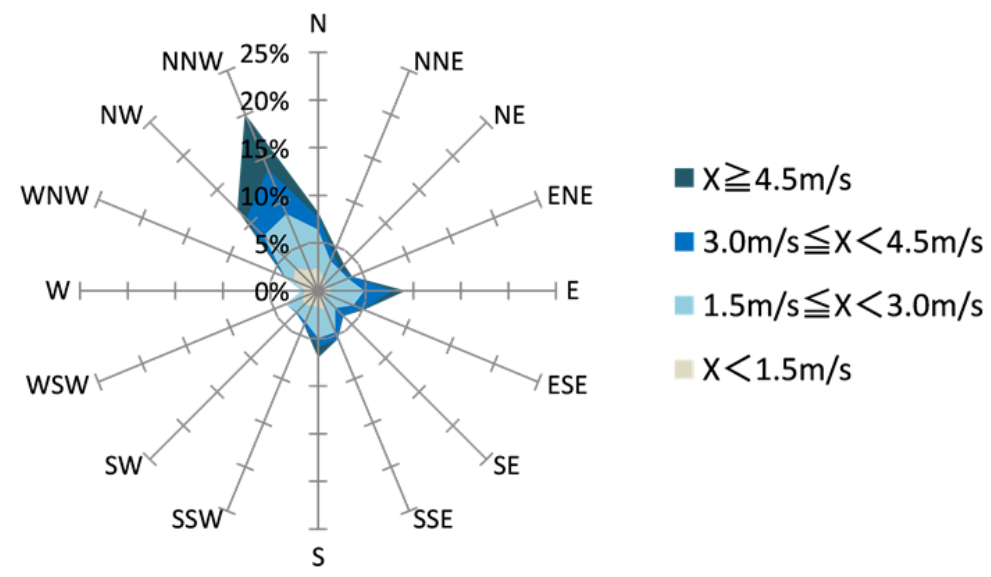

Figure 7. Wind rose by each wind speed class which is made by local meteorological station ( $X=$ wind speed) (Source: Authors) 


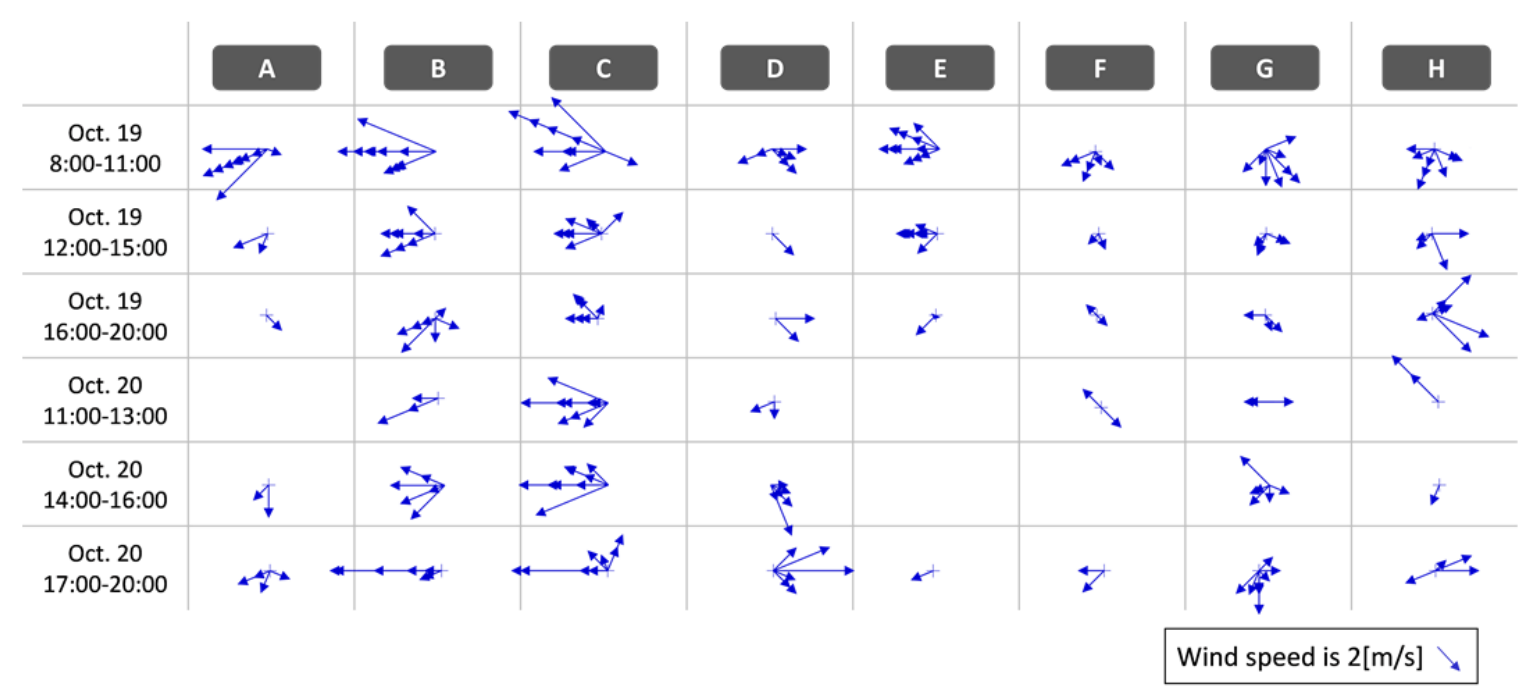

Figure 8. Wind direction and speed from points A to H (Source: Authors)

\section{Meteorological observation}

\section{I. Fixed-points observation}

According to Figure 2, nine (A to I) points for measuring wind directions and wind speed were considered. The wind direction and wind speed from points $A$ to $H$ were observed three times per hour.The wind direction, wind speed and temperature at point I were observed at an interval of 30 seconds, using the three-cup wind speed sensors supported by a data logger.

First, the results of maximum instantaneous wind speed, average wind speed, wind direction and temperature for point one were shown in Figure 6. The average temperature was about $20^{\circ} \mathrm{C}-25^{\circ} \mathrm{C}$; the most frequent wind direction was north or north-northeast; and the maximum instantaneous wind speed was $6 \mathrm{~m} / \mathrm{s}$ and average wind speed was $2 \mathrm{~m} / \mathrm{s}$. Temperature was the highest at around 15:00. It is considered that the observation point was located in the shaded area where high-rise buildings line up in the morning and was located in the sunny are in the afternoon. On weekdays the average wind speed was stronger in the morning than in the afternoon. On holidays the wind speed was strongest around 14:00 due to weather change at that time. Therefore, it was observed that strong winds usually blow from north or north-northeast in the morning across the target area. Also, Figure 7 shows the wind rose created by the local meteorological station using the hourly data in October.A comparison of the observed results and local meteorological station data revealed that the tendency of wind direction was almost same. The difference in the wind from the north or northnortheast seen in Figure 7 and the winds from the north or north-northwest seen in the local meteorological station data is considered to be due to the influence of the high-rise buildings surrounding point $\mathrm{I}$.

Second, Figure 8 presents the results of wind direction and speed from points $A$ to $H$ : the wind speed from points $A$ to $E$ was greater than the speed from points $F$ to $H$. From points $A$ to $C$, the wind nearly blew from the north, but from points $F$ to $H$, the wind blew from the east. It is considered that the wind blows from the north in the entire target area and the wind direction was different at each point due to the surrounding 
buildings. Furthermore, the wind blew from the north in the low-rise buildings in the east area; however, it blew from east in the high-rise buildings in the west area.

\subsection{Movement observation}

Movement observation was conducted by walking with instruments across the target area every 2 hours (9:00, I1:00, 13:00 and 15:00). The temperature distribution was understood by linking temperature data (thermocouple) to GPS (Global Positioning System) based locational data. Figure 9 shows the routes of movement observation and observation results on 20th. Two kinds of routes show the round trip from the east side of pedestrian deck to the furthermost point to the west side of "RELAX DECK". These results show that, at 9:00, the temperature around the "GARDEN DECK", "SHADE DECK" and "PUBLIC LIFE DECK" was relatively high but the temperature around the "RELAX DECK" was relatively low. The temperature difference between the east and west areas was slightly higher at II:00 and 13:00 than at 9:00. The temperature difference can be observed especially above the western part of the pedestrian deck. Potentially this is caused by the southern positioning of the pedestrian deck as it overshadowed by other buildings. At 15:00, the temperature difference between the eastern and western areas was slightly smaller than at I1:00 and 13:00, and the temperature on the northern side of "NOMADO DECK" which was relatively high. According to results for each time, the difference between the areas where the temperature was high and the area where the temperature was low in each time was largely influenced by the overshadowing effects of surrounding buildings. However, each time when the temperature difference between the eastern area and western area of the pedestrian deck was approximately I to 2 degrees, the temperature distribution did not have a noticeable difference.

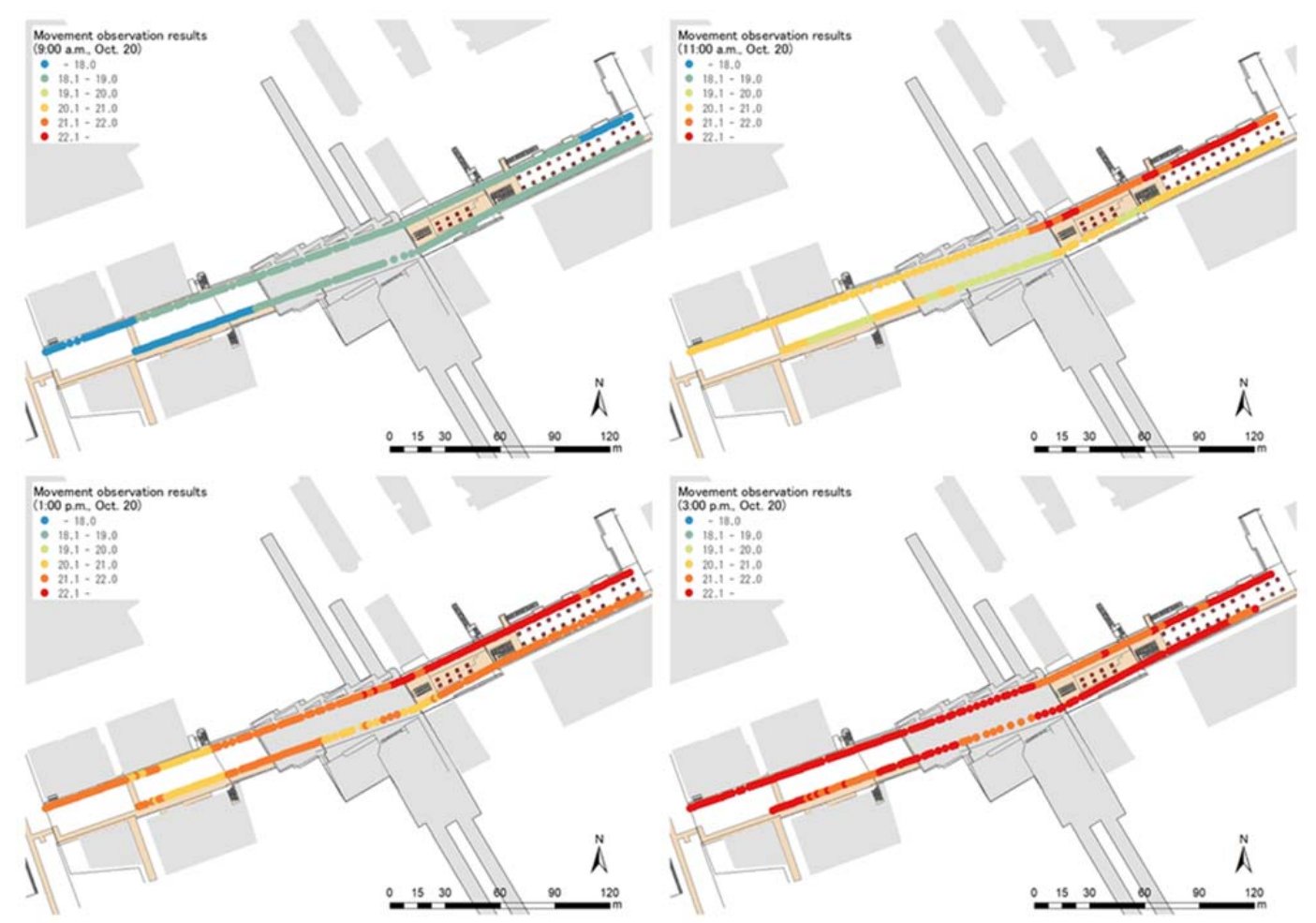

Figure 9. Routes of movement observation and observation results (Source: Authors) 


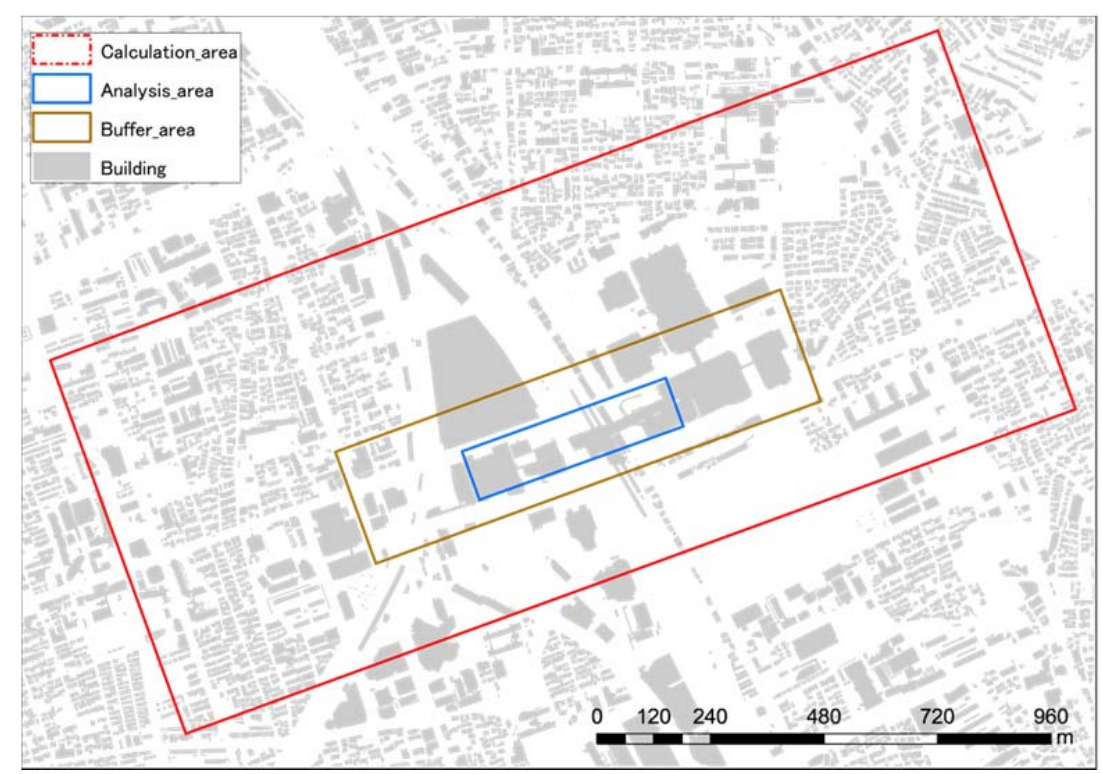

Figure 10. Calculation area, analysis area and buffer area in CFD simulation (Source: Authors)

Previous studies have shown that temperature, wind speed, and solar radiation have a significant effect on human behavior (Nakase and Kiyota, 1988, Akagawa et al., 2007). In this study, according to the above results of fixed-point observations and movement observations of wind and temperature, it was observed that the wind conditions in the target area vary depending on their strategic location. Furthermore, it was observed that the temperature difference is not so significant, but some temperature differences are considered to be due to the amount of solar radiation. Therefore, in the following chapters numerical simulations will introduced and discusses to gain a spatial understanding of the wind condition distribution and solar radiation distribution across the target area.

\section{Numerical simulation based on computational fluid dynamics (CFD)}

\section{I. Usage model and calculation condition}

The wind flow and amount of solar radiation was calculated using Autodesk computational fluid dynamics (CFD) 2019 (Albatayneh et al., 2017, Daemei et al., 2019). Autodesk CFD (formerly CFdesign) is a completely new thermal fluid problem design tool designed to make it easy for general designers to use CFD that has been used by fluid analysis experts. Many 3D CAD versions are available, such as Pro/ENGINEER, NX, Solid Works, Inventor, SpaceClaim, and Revit. In addition, it is possible to execute analysis in Autodesk CFD by outputting in the form of the intermediate file format Parasolid, ACIS in 3D CAD, or by linking through the included 3D modeling tool SimStudio Tools. Direct integration with 3D modeling kernels allows direct thermal and fluid analysis without data conversion. In addition, associability with 3D CAD is secured, it is possible to easily carry out multiple parameter studies with changes in dimensions, positions and shapes. As a result, it is possible to shorten the design period by repeating virtual prototyping, and it is possible to easily lead a solution to problems that are difficult to experiment on and visualize. In this study, the input building data of simulation was compiled based on the plan and field survey result by using Revit. The calculation area 
was a rectangle within the target area (Figure 10). The size of each area is set by using previous studies as a reference (Takebayashi, 20I5, Hayashi et al, 2014 \& Houda, et al., 2017). Moreover, the target area was partitioned using the function in which suitable mesh size is calculated automatically. The calculation was performed in each mesh. First, for the wind flow simulation, the turbulent model was similar to the k- $\varepsilon$ model. The wind-flow simulation in this study did not consider the heat. Furthermore, the local meteorological station hourly data was of the wind speed and the inflow condition was a wind speed of $2.2 \mathrm{~m} / \mathrm{s}$ (wind direction: north-northwest) with a height of $10 \mathrm{~m}$ by power law (n: 2). Second, for the amount of solar radiation simulation, the emissivity $(0.3)$ and sky conditions were set.

\subsection{Simulation results}

Figure II and Figure 12 show the results of wind speed, wind direction and amount of solar radiation. The results of wind speed and wind distribution used in the examples were collected at about $2 \mathrm{~m}$ height and the amount of solar radiation was collected at 9:00, I I:00, and 13:00. In addition, the comparison of wind speed and observation direction discussed previously elucidated that the difference between the simulation results is relatively small. First, focusing on the wind direction, the wind blows from north, north-northeast or north-northwest on the "GARDEN DECK", "SHADE DECK", "PLAY DECK". The wind blows from east on "PUBLIC LIFE DECK" and "NOMADO DECK" as the area is surrounded with low buildings. It revealed that on the "PLAY DECK" and "NOMADO DECK" area, the wind was blowing from the northern direction and changed to the east mainly due to the positions of surrounding buildings. Moreover, focusing on the wind speed, the wind speed on the "PLAY DECK" area, the south area of "NOMADO DECK", "SHADE DECK" area and "RELAX DECK" area was relatively high. On the "NOMADO DECK" area, the wind speed differed depending on the area.

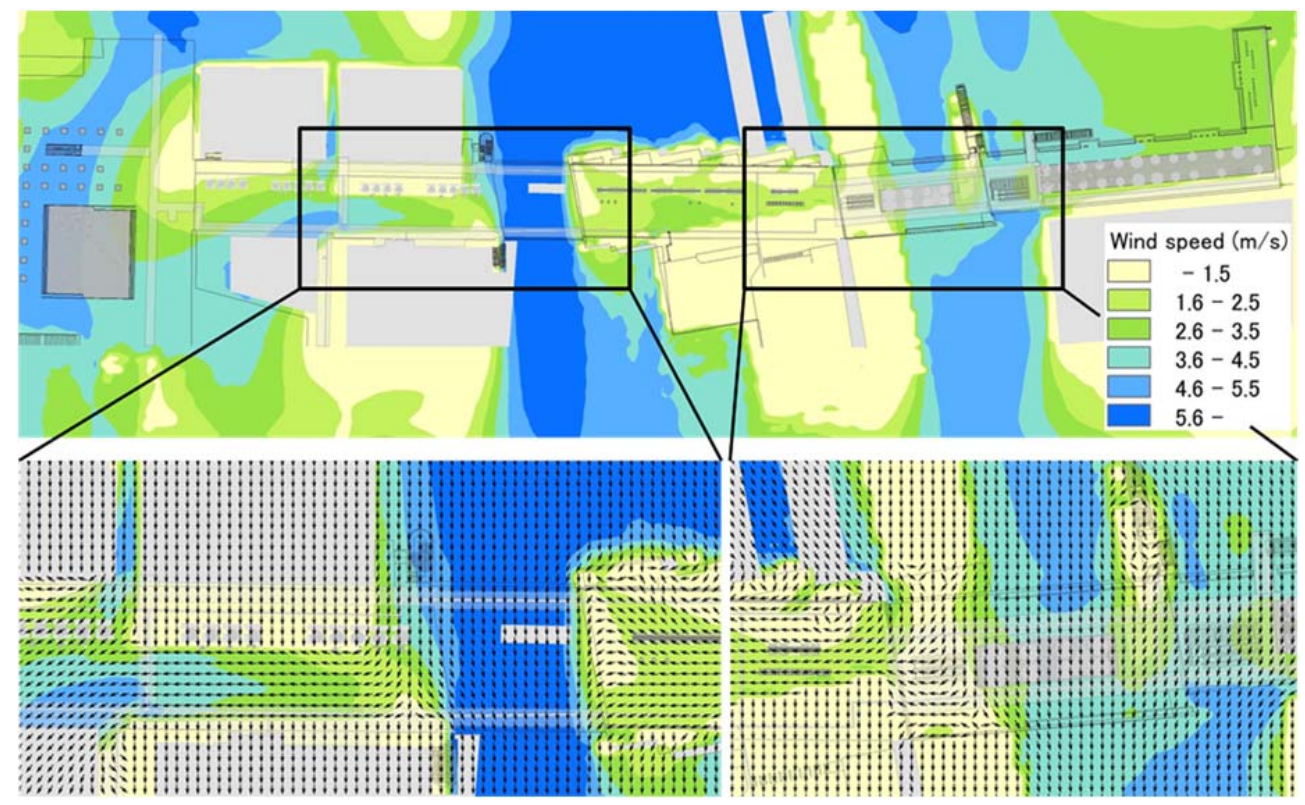

Figure II. Simulation results of wind speed and wind direction (Source:Authors) 


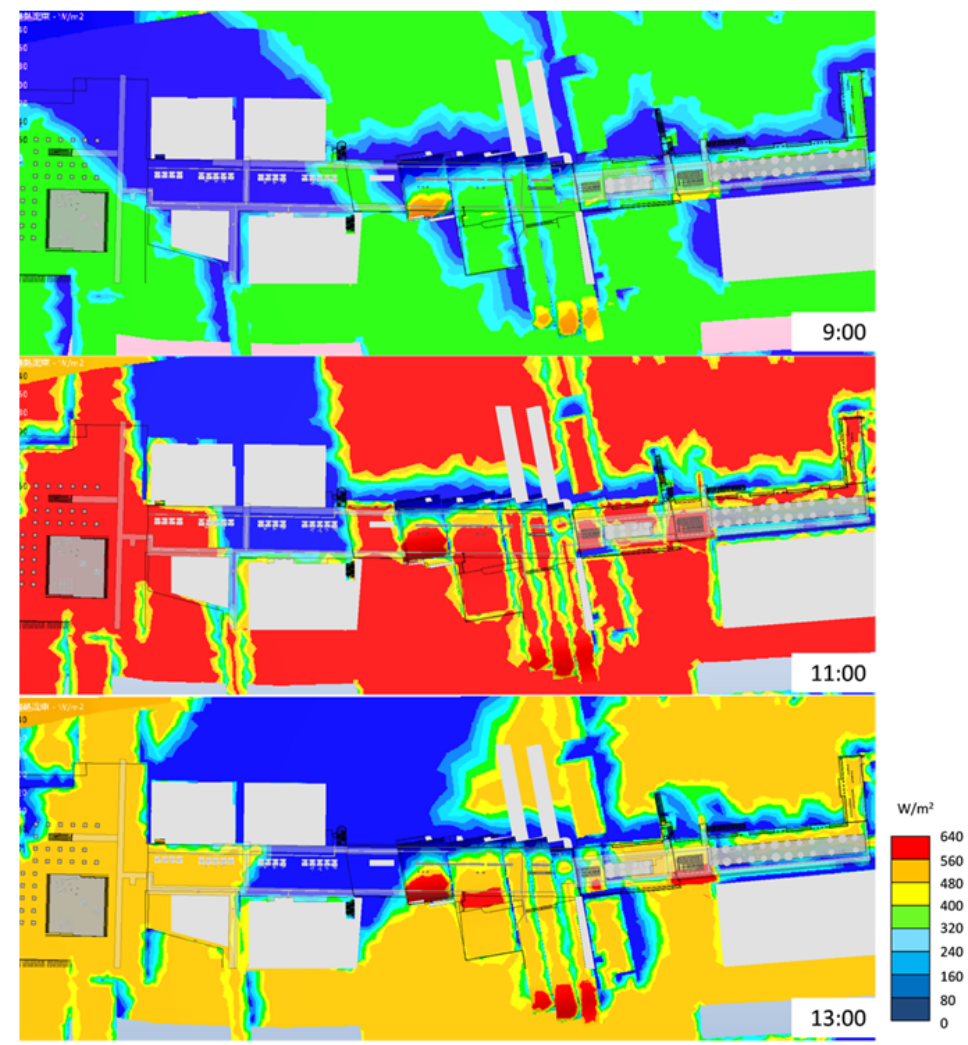

Figure 12. Simulation results of the amount of solar radiation (Source: Authors)

Second, according to the amount of solar radiation results, the amount of solar radiation was highest at around II:00. It can be observed that the location of the shadow caused by the building changes with the movement of the sun. In this target area there were two types of spaces: those with roof and those without roof. The areas with roofs were located on the "PUBLIC LIFE DECK", partly on the "SHADE DECK" and the northern or southern side of the pedestrian deck. Moreover, there was shade created by a tree on the "RELAX DECK". As for areas without roof, the amount of solar radiation on the "NOMADO DECK" differed. Specifically, in the morning, the eastern side on the "NOMADO DECK" area, which was also included in the "PLAY DECK", was in located in the shade. In the afternoon the western side of the "NOMADO DECK" area was located in the shade. Overall, the shadows created are a result of the high-rise buildings close to the "NOMADO DECK" area.Also, the amount of solar radiation on "GARDEN DECK" differed. It can be observed that the amount of solar radiation at the northern side of the pedestrian deck was greater than that on the south side.

The next section presents an analysis between the numerical simulation results and the distribution of stationary people for a better understanding of the area in which human activity is generated from the perspective of climatic characteristics.

\section{Relationship analysis and climate zoning}

\section{I. Relationship analysis}

In this section, the data of stationary people other than "PUBLIC LIFE DECK" is used as 
the number of stationary people staying at this deck is greatly influenced by the station which has a slightly different characteristic compared to the other decks. First, Figure 13 shows the number of stationary people by each wind speed class on weekdays and holidays using the activity survey results and wind simulation results. In this study, the wind speed class interval was set to $0.5 \mathrm{~m} / \mathrm{s}$. The results for the weekdays revealed that the number of stationary people was relatively low in the area where winds were relatively high. On holidays, when the wind speed is $3 \mathrm{~m} / \mathrm{s}$ or less, the number of stationary people increases as the wind speed increases. When the wind speed is $3 \mathrm{~m} / \mathrm{s}$ or more, the number of stationary people decreases as the wind speed increases.
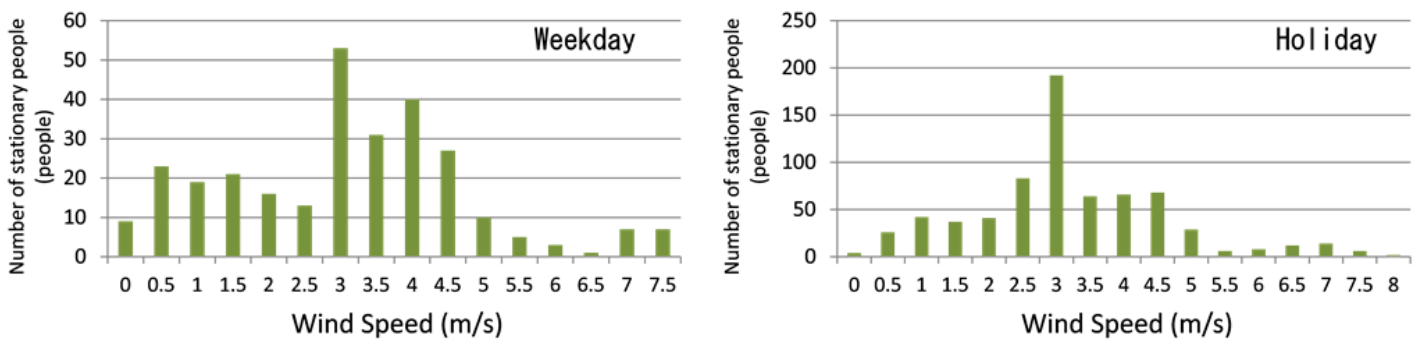

Figure 13. Number of stationary people by each wind speed class on weekday and holiday (Source: Authors)
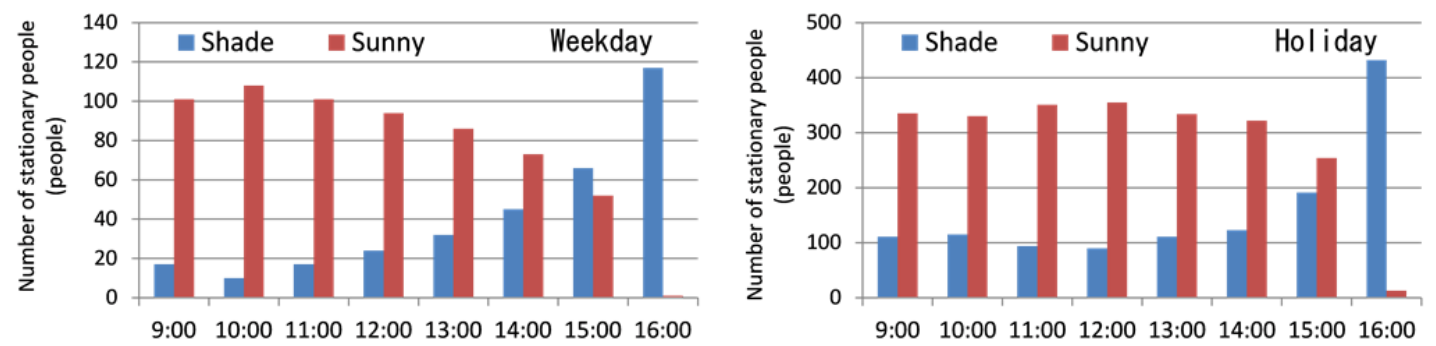

Figure 14. Number of stationary people in the shade and sunny place on weekday and holiday (Source: Authors)
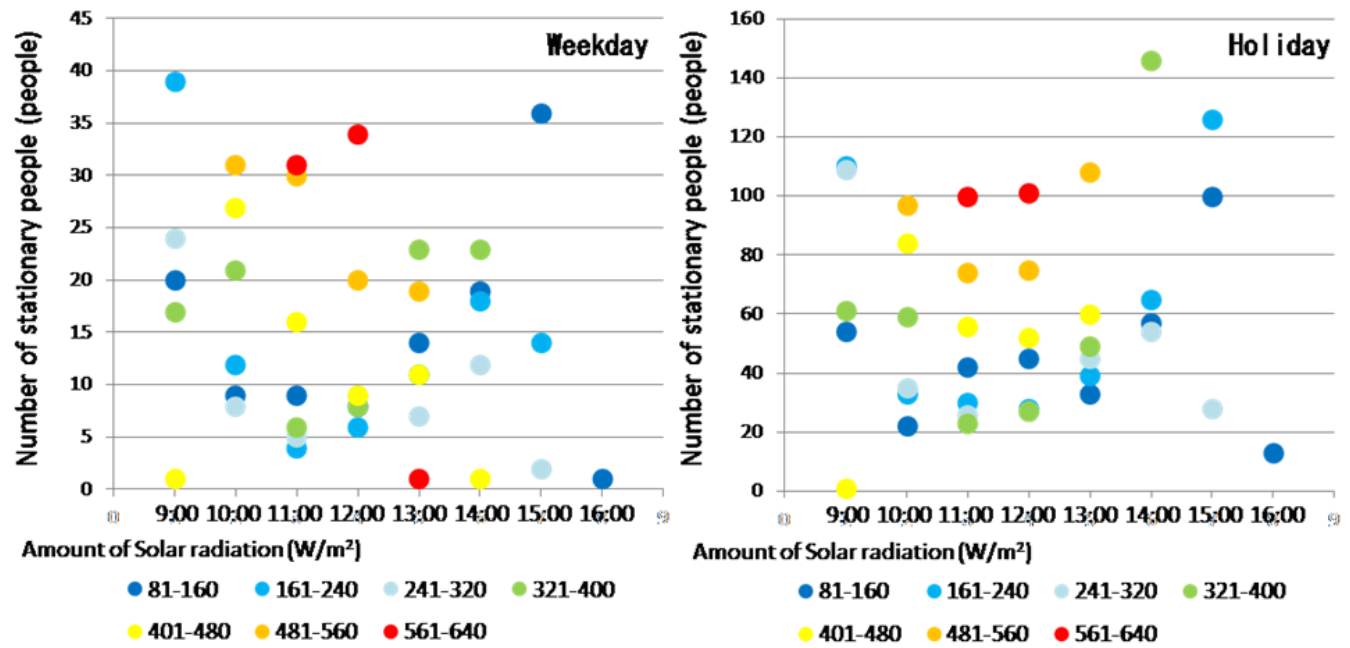

Figure 15. Number of stationary people by each amount of solar radiation wind speed class on weekday and holiday (Source: Authors) 
The same trend was observed on holidays and on weekdays. Thus, the area in which the wind speed range was between $0.0 \mathrm{~m} / \mathrm{s}$ to $3.0 \mathrm{~m} / \mathrm{s}$ people easily stayed outside during this season. Second, Figure 14 shows the number of stationary people in the shade and on sunny places during weekdays and holidays using the activity survey results and the amount of solar radiation simulation results. In this study, shady areas were available under the roofs or street trees with less than $80 \mathrm{~W} / \mathrm{m}^{2}$. The results highlight that the number of stationary people in the sunny place was higher than that in the shady areas during evening hours. Furthermore, during the evening the opposite trend was observed as most of the target area was fully shaded. Thus, the sunny area or solar radiation environment was considered to be the area of choice where people easily stay outside during daytime as part of this season. In addition, the number of stationary people and the amount of solar radiation class on weekdays as well as holidays is shown in Figure 15. From this figure, it shall be concluded that the greater the amount of solar radiation during this season, the greater the number of visitors, especially on holidays.

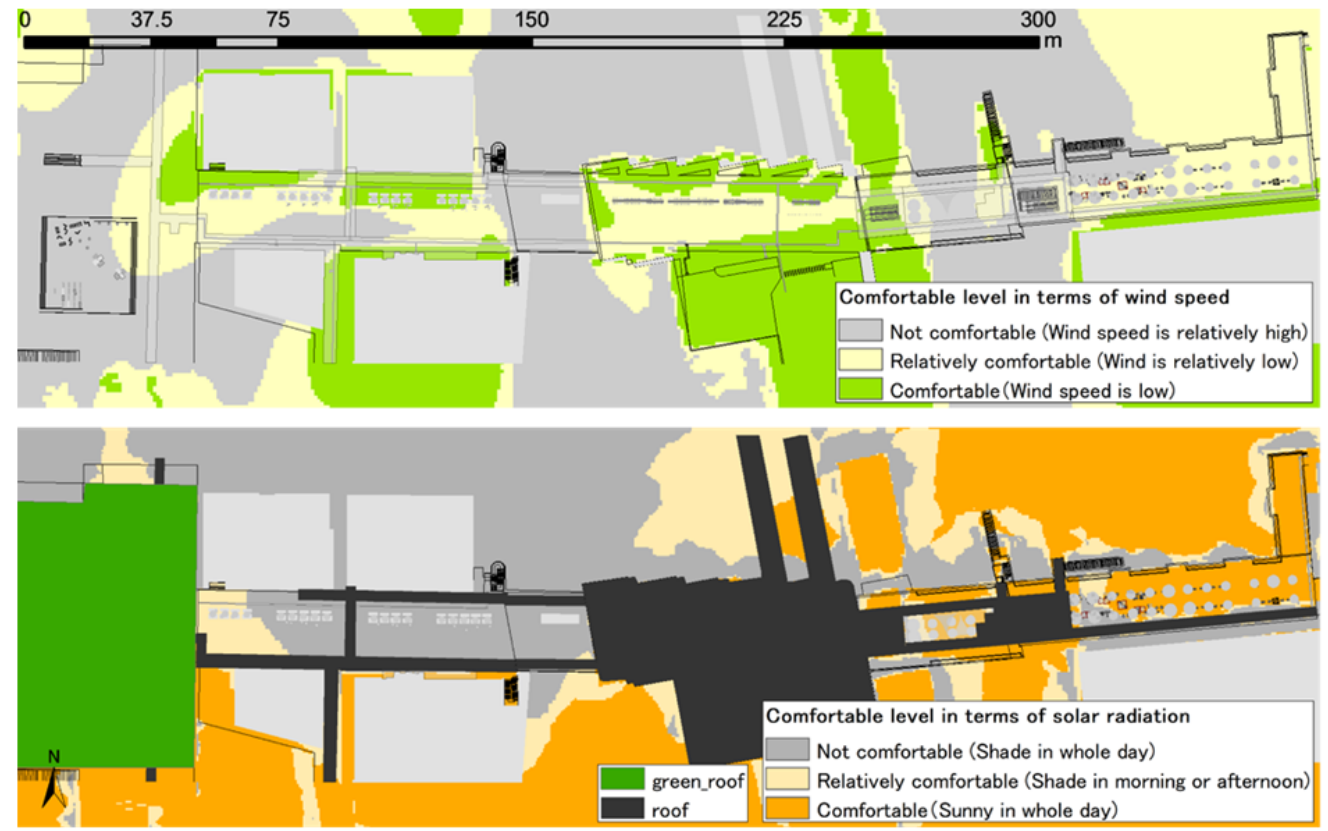

Figure 16. Climate zoning and street environmental climate map (Source: Authors)

\subsection{Climate zoning related to wind speed and solar radiation}

First, climate zoning related to wind speed and solar radiation is discussed based on the results of the relationship analysis (Figure 16). Zoning was first performed using the threshold of the wind speed, $3.0 \mathrm{~m} / \mathrm{s}$, the relationship between the number of stationary people and wind speed, and then based on the difference in shade and sunny places at each time. The area where the wind speed is less than $3.0 \mathrm{~m} / \mathrm{s}$ was divided in two parts and the sunny place is divided into a sunny area during morning hours and another sunny area in the afternoon. Based on these zoning and in terms of wind environment there are many comfortable areas for stationary behavior in the northern or southern side of the "PUBLIC LIFE DECK" and "NOMADO DECK" and the southern side of the "GARDEN DECK". Moreover, there were many uncomfortable areas for stationary behavior on the "SHADE DECK" and "PLAY DECK". In terms of the solar radiation 
environment, there were many comfortable areas for stationary behavior on the "SHADE DECK" and "GARDEN DECK". In addition, there are many uncomfortable areas for stationary behavior on "PLAY DECK" and "NOMADO DECK". Second, the street environmental climate map was created by using the climate zoning; the areas where people easily stay outside during this season. Each zone is shown in Figure 16. The map in terms of wind environment shows three different zonings: the comfortable zone, relatively comfortable zone and not comfortable zone.A comfortable area is an area where the wind speed is $0.0 \mathrm{~m} / \mathrm{s}$ or higher, and up to $1.5 \mathrm{~m} / \mathrm{s}$. The relatively comfortable zone is an area where the wind speed is $1.5 \mathrm{~m} / \mathrm{s}$ or higher, and up to $3.0 \mathrm{~m} / \mathrm{s}$, and the not comfortable area is an area with a wind speed of $3.0 \mathrm{~m} / \mathrm{s}$ or more in this study. The map of solar radiation environments shows three zonings: the comfortable zone, relatively comfortable zone and not comfortable zone. The comfortable zone is an area that is sunny throughout the whole day. The relatively comfortable zone is an area that is sunny in the morning or afternoon, and the not comfortable area is covered in shade throughout the whole day.

\section{Conclusion}

This study aimed to better understand the relationship between numerical simulation results and investigation results of the actual user behavior and develops a street environmental climate map for stationary people to design and plan for more comfortable public spaces by considering climatic characteristics in the SNUC area. The results were as follows:

I) Investigation of the actual users' behavior revealed that there are many pedestrian and stationary people in front of stations and the number of stationary people in the eastern area was higher than that in the western area.

2) Meteorological observations indicated that the climatic characteristics and factors influence the actual user behavior and differed according to places in the street area.

3) The relationship analysis elucidated that during autumn season which average temperature is around $20^{\circ} \mathrm{C}$, people tend to stay outside in sunny areas as well as in areas where the wind speed ranged from $0 \mathrm{~m} / \mathrm{s}$ to $3 \mathrm{~m} / \mathrm{s}$.

The study limitations and prospects for future research are as follows:

1) This study was conducted in autumn when the maximum and minimum temperatures are about $22{ }^{\circ} \mathrm{C}$ and $15{ }^{\circ} \mathrm{C}$, respectively. However, the area where people easily stay outside differs during each season. Therefore, it is necessary to further consider other seasons for better design and plan more comfortable public open spaces with the use of pilot projects.

2) This study highlights that environmental factors affect the number of stationary people. In the future, it might be necessary to analyze the relationship between other factors and environmental simulation results. For example, those are stationary times or stationary behavior types.

3) Although the wind environment map and the solar radiation environment map of this study were made separately, it is necessary to overlay them from now on and to determine an environmentally appropriate place when conducting social space experiments. 


\section{Acknowledgements}

This study was supported by Grant-in-Aid for Japan Society for the Promotion of Science Fellows (17J07605). The authors thank Urban and Architectural Planning Laboratory in Department of Architecture, Graduate School of Engineering, Hiroshima University, especially Ryosuke Okada and Shuhei Ota on the CFD simulation. Also, the Public Life Fes Saitama Shintoshin Center 2018 and its investigation are being carried out in cooperation with Saitama City, the Public Life Fes Saitama Shintoshin Center Executive Committee, Saitama Shintoshin Center Development Council, UDCO Urban Design Center OMIYA, and Sotonova.

\section{References}

Akagawa, H., Fukumi, K., Kubota,T., Takebayashi, H., \& Moriyama M. (2007). Study on thermal environment and behavior of visitors at a large rooftop garden on a commercial building in summer, Journal of Environmental Engineering, 72(6II), pp. 67-74 (in Japanese) https://doi.org//0.3130/aije.72.67 I.

Albatayneh, A., Alterman, D., Page, A. \& Moghtaderi, B. (2017). Discrepancies in Peak Temperature Times using Prolonged CFD Simulations of Housing Thermal Performance, Energy Procedia, I I5, pp. 253-264 https://doi.org/l0.1016/j.egypro.2017.05.023.

A.T. P.Wai,Vilas N., Sohee M. K. (20I8). Multi-stakeholder and multi-benefit approaches for enhanced utilization of public open spaces in Mandalay city, Myanmar, Sustainable Cities and Society, 37, pp. 323-335 https://doi.org/10.1016/j.scs.2017.10.038.

Daemei, A. B., Khotbehsara, E. M., Nobarani, E., M. \& Bahrami, P. (2019). Study on wind aerodynamic and flow characteristics of triangular-shaped tall buildings and CFD simulation in order to assess drag coefficient, Ain Shams Engineering Journal, I0(3), Pp. 54 I-548, https://doi.org/10.1016/j.asej.2018.08.008.

Hayashi, K., Tanaka, T., Inachi, S. \& Yasukawa, M. (20I4). Analysis on the effect of urban form on outdoor temperature and ventilation condition in coastal densely wooden built-up area, Journal of Environmental Engineering, 79(698), pp. 349-356 (in Japanese) https://doi.org// 0.3130/aije.79.349.

Hiroyoshi, Morita, H., Inenaga, S., Fujimori, M., Murayama, A. \& Endoh,Y. (20I5).Analysis on effect of sidewalk widening with wood deck on auto traffic and pedestrian behavior: Case study of social experiments called Choja-machi wood terrace, Journal of the City Planning Institute of Japan, 50(3), pp. 709-7I 4 (in Japanese) https://doi.org/I0.I I36I/journalcpij.50.709.

Houda, S., Belarbi, R. \& Zemmouri, N. (2017). A CFD Comsol model for simulating complex urban flow, Energy Procedia, 139, pp. 373-378 https://doi.org/I0.1016/j.egypro.2017.11.224.

Izumiyama, R., Akiyama, H. \& Kobayashi, M. (20I5). Study on the application and management of "privately owned public spaces" in the urban central area:Through research and analysis to community management organization registration system the "Tokyo Municipal Ordinance on promoting the creation SYARETA-MACHINAMI of Tokyo. Journal of Architecture and Planning, 80(7/0), pp. 915-922 (in Japanese) https://doi.org//0.3130/aija.80.915. 
Izumiyama, R., Nakano, T., Nemoto, H. (20I6). The activity evaluation method of public space by the human oriented perspective: Focusing on activity investigation of "IKEBUKURO east green boulevard sidewalk café pilot project in 2015 spring." Journal of Architecture and Planning, 8I (730), pp. 2763-2773 (in Japanese) https://doi.org//0.3130/aija.8I.2763.

Izumiyama, R., Nakajima, S., Koizumi, H. (2018). Effort and issues of "Kanda Police Street Bustling Pilot Program 2017" as "Participatory Pilot Program Method" in public space utilization, Journal of the City Planning Institute of Japan, 53(3), Pp. I223-I 230 (in Japanese) https://doi.org/10.11361/journalcpij.53.1223.

Jan G. \& Gehl Architects (2009). Downtown Seattle 2009, Public Spaces \& Public Life.

Lydon, M. \& Garcia,A. (20I5). Tactical urbanism. Short-term action for long-term change, Island Press.

Li, D., Okudaira, J., Kwak, D. \& Kitahara,T. (20I2). Study on the Change of Staying behavior in Pedestrian underpass: Underground parasol gallery in front of Chiba station, Journal of Architecture and Planning, 77(677), pp. I681-1687 (in Japanese) https://doi.org/I0.3130/aija.77.168I.

Nakase, I. \& Kiyota, M. (1988) Relationship between thermal factors and human behavior, Journal of the Japanese Institute of Landscape Architects, 5 I (5), Pp. 216-22I (in Japanese) https://doi.org//0.5632/jila |934.5I.5_216.

Okamatsu, M. \& Mouri,Y. (20I5).Verification of the effect of Utilizing a vacant lot as "a Liveliness Open Space" in a neighborhood based mall: Case study of a morning market event at a neighborhood based mall in Ichiki-Kushikino city, Kagoshima prefecture, Journal of the City Planning Institute of Japan, 50(3), pp. 1069-I076 (in Japanese) https://doi.org//0.11361/journalcpij.50.1069.

Takebayashi, H. (20I5). Evaluation of wind environment in street canyon for use in urban climate map, Journal of Environmental Engineering, 80(7I5), pp. 795-80I (in Japanese) https://doi.org// 0.3130/aije.80.795.

Tokyo Metropolitan Government (n.d.) Special Urban Renaissance Districts, Tokyo Metropolitan Government. http://www.toshiseibi.metro.tokyo.jp/pdf_e/0I5.pdf. 